\title{
Does trait mindfulness level affect quitting cannabis use? A six week follow-up study
}

\author{
Salih Cihat Paltun¹, Neslihan Altunsoy², Sinem Duran Özdemir³, Ihsan Tuncer OkaY4 \\ ${ }_{1}^{1}$ Numune Training and Research Hospital/Alcohol and Drug Dependence Treatment Department, Ankara, Turkey. \\ 2 Boylam Psychiatry Clinic, Ankara, Turkey. \\ ${ }_{3}^{3}$ Sevket Yilmaz Training and Research Hospital Psychiatry Department, Bursa, Turkey. \\ ${ }_{4}^{4}$ Numune Training and Research Hospital Psychiatry Department, Ankara, Turkey. \\ Institution where the study was conducted: Numune Training and Research Hospital/Alcohol and Drug Dependence Treatment Department, Ankara, Turkey.
}

Received: 03/14/2016 - Accepted: 10/05/2017

DOI: 10.1590/0101-60830000000139

\begin{abstract}
Background: Only 29\% of cannabis dependent individuals seek treatment, yet significant decreases in cannabis use are seen in 31-36\% of individuals that seek treatment. Follow-up studies have found that over $60 \%$ in substance use disorders end in relapse, leading to potentially chronic and relapsing cases. New and effective therapies should be researched in order to increase the success of relapse prevention treatments. Objective: In this study we aimed to evaluate the relationship between trait mindfulness level, substance dependence severity and quitting cannabis use. Methods: A hundred and sixty four patients, diagnosed with cannabis dependence, were involved in the study; socidemographic datas were recorded and Addiction Profile Index (API), Mindfuness Attention and Awareness Scale (MAAS) were carried out. Results: We found that the trait mindfulness level is significantly related with quitting cannabis use. Discussion: Trait mindfulness may be an important determining factor of the ability to quit substance use and achieve remission.
\end{abstract}

Paltun SC et al. / Arch Clin Psychiatry. 2017;44(6):139-44

Keywords: Dependence, mindfulness, cannabis.

\section{Introduction}

Cannabis use has proliferated since ancient times. It is currently the most commonly used illicit drug that affects human psychological health. Many clinical trials have shown that cannabis is a gateway drug to use of other substances and has comorbidity with other psychiatric disorders, especially schizophrenia ${ }^{1-6}$. The psychosocial treatment models for cannabis dependence include motivational enhancement therapy, cognitive behavioral therapy and contingency management for adults.

In addition, brief strategic family therapy, family behavior therapy, family support network intervention and community reinforcement approach counseling, functional family therapy, multidimensional family therapy, and multisystemic therapy are other psychosocial treatment models for youths ${ }^{7}$.

Only $29 \%$ of cannabis dependent individuals seek treatment ${ }^{8}$, yet significant decreases in cannabis use are seen in $31-36 \%$ of individuals that seek treatment 9,10 . Follow-up studies have found that over $60 \%$ in substance use disorders end in relapse, leading to potentially chronic and relapsing cases ${ }^{11-13}$. Treatment models have been developed to prevent relapse. However, clinical data has shown that treatments used in substance use disorders provide far from satisfactory results ${ }^{14}$. Although cognitive behavioral therapy ${ }^{15}$ shows significant short-term effects on many substance users, 50-70\% relapse ratio is still a serious problem of this therapy model ${ }^{16}$. New and effective therapies should be researched in order to increase the success of relapse prevention treatments ${ }^{15}$.

In 2004, Hayes ${ }^{17}$ described the third wave of cognitive behavioral therapies ${ }^{17}$ as mindfulness-based therapies; new research and applications using mindfulness concepts are being developed for substance use disorders ${ }^{18}$. Although there are multiple definitions, mindfulness is commonly defined as the capacity to place one's attention and focus on the present moment in a non-judgmental, non-reactive, and compassionate manner ${ }^{19-22}$. Mindfulness has been described as a capacity that is present since birth and that can be developed by meditation practices and mindfulness-based interventions ${ }^{19,23,24}$. Mindfulness-based relapse prevention (MBRP) ${ }^{25}$, a new treatment model, has been recently developed; this model combines mindfulness meditation and cognitive-behavioral relapse prevention techniques ${ }^{26}$. The mindfulness practices of MBRP aim to increase an individual's awareness of external triggers and internal cognitive and affective processes; increase the ability to tolerate challenging cognitive, affective, and physical experiences 25 ; and enhance metacognitive abilities ${ }^{27}$. Recent studies suggest several possible mechanisms about mindfulness based interventions in addictive behaviours. Neurobiological mechanisms in areas associated with craving, negative affect, and substance use relapse may be affected by mindfulness training, altering basic neurobiological processes related to reactive behaviors. Data from clinical trials likewise suggest mindfulness training may lead to decreases in self-reported severity of factors related to relapse such as anxiety, depression, and stress, decreases in both craving and reactivity to craving and an improved ability to decouple the drinking impulse from drinking behavior ${ }^{28}$. Recent theories have emphasized the multi-dimensional nature of dependence and how it is influenced by positive/negative reinforcement and automaticity. Indeed, mindfulness is thought to be linked with dependence by enhancing attention control and reducing automaticity. Tiffany's cognitive processing model of addiction is an important theory that describes the relationship between mindfulness and substance use. This theory outlines how routine behaviors, including substance use, become automatic over time and thus difficult to refrain from; continued use or relapse stems from the inability to disrupt these automatic behavioral routines ${ }^{29}$.

The negative reinforcement model of relapse suggests that negative sensations are the most powerful motivator of chronic substance use. According to this model, individuals use substances to avoid aversive moods, such as anxiety and depression ${ }^{30}$. This theory intersects with the self-medication theory that suggests that individuals use substances to avoid aversive experiences and sustain positive experiences ${ }^{31}$. 
The effect of MBRP and modified MBRP protocols in substance use disorders was evaluated in four independent research studies. MBRP treatment was reported to decrease substance use or events related with substance use, such as cravings and responses to substance triggers ${ }^{27,32-35}$. Some researchers have proposed that mindfulness reduces the necessarity of avoiding aversive sensations by increasing positive sensations and reducing negative sensations ${ }^{36-38}$. Trait Mindfulness has been thought to be a naturally occurring difference among individuals or a dispositional trait 24 that can be developed through meditative practices and mindfulness-based interventions ${ }^{19,23}$. Individuals with high levels of trait mindfulness are theorized to be better able to view aversive experiences as being transient and to be less likely to engage in substance use behaviors as a means of coping with such experiences $20,39,40$.

Based on this information, we hypothesized that the level of trait mindfulness of individuals are positively related with their capacity to quit cannabis use and negatively related with their severity of cannabis dependence. In this study we aimed to evaluate the relationship between trait mindfulness level and cannabis use of two groups during the follow up period; group continue (GC) and group quit (GQ). In addition, we analyzed the relationship between trait mindfulness and severity of cannabis dependence in both groups.

\section{Methods}

\section{Participants}

Outpatients that were sent to our treatment center by the probation office were under probation due to illegal substance use and were involved in the study after signing an informed consent form. The patients were between 18-65 years old, could write and read and were diagnosed with cannabis dependence according to the Diagnostic and Statistical Manual of Mental Disorders, Fourth Edition - Text Revision (DSM IV-TR). The study ran from 01 January 2014 to 31 March 2014 at the Department for the Treatment of Alcohol and Substance Use Disorders of Ankara Numune Education and Research Hospital. Patients with educational and language problems that prevented diagnostic psychiatric interviews, another axis-I diagnosis other than cannabis dependence, diagnosis of mental disorder due to general medical conditions, or mental retardation were excluded. The approval for the study was obtained on 18 December 2013 from the Presidential Ethics Committee of Ankara Numune Education and Research Hospital (decision number 70/2013).

\section{Measures}

After the patients signed informed consent and accepted participation in the study, sociodemographic data on patients were recorded. To measure the dependence severity, the participants were asked to fill out the Addiction Profile Index (API) developed by Kultegin Ogel, Cuneyt Evren, Figen Karadag and Defne Tamar Gurol. The API consists of the following five subscales of substance use: the characteristics of substance use, dependency diagnosis, the effects of substance use on the user, cravings, and motivation to quit using substances ${ }^{41}$. The API total scores are divided into three categories that describe the severity of dependence: a) $<12$ points indicate low dependence, b) 12-14 points indicate moderate dependence, and c) $>14$ points indicate high dependence ${ }^{41}$. The participants were also asked to self-asses themselves on the Mindfulness Attention and Awareness Scale (MAAS). This scale, developed by Brown and Ryan ${ }^{24}$, evaluates the level of mindfulness and consists of 15 items; high resulting values indicate a high level of mindfulness. The mean MAAS value of the whole sample was accepted as the determining threshold of high and low mindfulness. A validity and reliability study was conducted according to the Turkish study by Zumra Ozyesil et al.42. The MAAS measures only the "acting with awareness" facet of mindfulness; without "observing", "describing" and "accepting without judgement" facets. In addition to the sociodemographic data and the calculated API and MAAS scales, urine tests of cannabis metabolites were performed to evaluate cannabis use. All these tests were completed in the first meeting, after which the follow-up period began. The follow-up period consisted of 3 meetings during the six weeks after the first meeting, as one meeting every two weeks. In all meetings, urine tests were repeated. During the follow-up period, mindfulness-based interventions were not conducted with the sample.

\section{Procedures}

We followed up patients diagnosed with cannabis dependence for six weeks following diagnosis. The individuals involved in the study were further divided into two groups at the end of the follow-up period based on the results of the urine test of cannabis metabolites. During follow-up, excluding the first meeting, individuals with at least one positive urine test were included in Group Continue (GC), and individuals with negative tests were included in Group Quit (GQ). We aimed to evaluate the relationship between trait mindfulness level and cannabis use of two groups. At the beginning of the study, 190 cannabis dependent-patients were undergoing treatment at our study center, although 2 patients could not read or write, 4 patients refused to join, and 20 patients could not complete the follow-up period and were thus excluded. In total, 164 individuals were included in the study. Only male patients were included, as no female patients diagnosed with cannabis dependence visited our center during the study period.

\section{Data analysis}

We evaluated the relationship between dependence severity and trait mindfulness cross sectionally at the first meeting and followed up the patients for six weeks to assess the relationship between trait mindfulness and cannabis use by repeated urine tests. All statistical analyses were conducted with IBM SPSS for Windows, version 21.0. Numerical variables were summarized as the mean \pm standard deviation; categoric variables were summarized as numbers and percentages. Parametric hypothesis tests (normality and homogeneity of variances) were performed before comparison of the groups to test if their variances were equal. To determine differences in the numerical variables of the two independent groups, a t-test was applied for parametric data. The Kruskal Wallis test was also applied; this test is used for comparing groups of two or more independent samples. The relationship between numerical variables was determined by calculating the Pearson correlation coefficients. The significance level was determined as $\mathrm{p}<0.05$. The relationship between cannabis dependence severity and trait mindfulness of two groups (GC and GQ) were analyzed by t test. The relationship between API total score and MAAS scores in the whole sample analyzed by pearson correlation coefficient. The relationship between API-subgroups and trait mindfulness in the whole sample was analyzed by kruskal wallis test.

\section{Results}

In our study, GC was composed of 79 patients who tested positive for cannabis in at least one of their urine samples (excluding the first meeting) during the 6-week follow-up period. GQ was composed of 85 patients who quit substance use during the follow-up period and thus qualified as early partial/full remission candidates; none of their urine tests (excluding the first meeting) were positive for cannabis.

The mean age of GC was $29.1 \pm 8.5$ and of GQ was $26.7 \pm$ 7.0. All patients were male. No significant differences were found between two groups in regard to the sociodemographic data on age, marital status, educational level, living situation, and job status in the previous year.

Fifty-two individuals (65.8\%) in GC considered cannabis to be a problem in their life in comparison with 45 individuals (52.9\%) in GQ; the difference in this parameter was not statistically significant (Table 1). Fourteen individuals (17.7\%) in GC had a history of legal 
problems related with cannabis use in comparison with 5 individuals (5.9\%) in GQ; this difference was statistically significant, with a greater ratio of individuals experiencing legal problems in GC (Table 1).

Table 1. Comparison of group continue and group quit due to having history of legal problems depending on cannabis use and thinking cannabis use is a problem

\begin{tabular}{|l|c|c|c|}
\hline & $\begin{array}{c}\text { Group } \\
\text { Continue } \\
(n=79)\end{array}$ & $\begin{array}{c}\text { Group } \\
\text { Quit } \\
(n=85)\end{array}$ & $p^{*}$ \\
\hline $\begin{array}{l}\text { I have lived legal problems depending } \\
\text { on cannabis use }\end{array}$ & $14(17.7 \%)$ & $5(5.9 \%)$ & 0.034 \\
\hline Cannabis use is a problem in my life & $52(65.8 \%)$ & $45(65.8 \%)$ & 0.228 \\
\hline
\end{tabular}

$\mathrm{p}^{*}$ : $\mathrm{p}$ value obtained bay applying chi-square test.

The relationship between level of trait mindfulness and history of using substances other than cannabis was examined for the whole sample; trait mindfulness level was significantly lower in the group that had history of using substances other than cannabis (Table 2).

Table 2. The relationship between MAAS score and history of substance use other than cannabis in whole sample

\begin{tabular}{|l|c|c|c|}
\hline & $\begin{array}{c}\text { Do not have history of } \\
\text { substance use other than } \\
\text { cannabis } \\
(n=48)\end{array}$ & $\begin{array}{c}\text { Have history of substance } \\
\text { use other than cannabis } \\
(n=116)\end{array}$ & $p^{*}$ \\
\hline $\begin{array}{l}\text { MAAS } \\
\text { (Ave } \pm \text { SD) }\end{array}$ & $76.0 \pm 12.8$ & $69.6 \pm 15.2$ & 0.012 \\
\hline
\end{tabular}

MAAS: Mindfulness Attention Awareness Scale.

*: p value obtained by applying $t$ test.

Ave: average; SD: standard deviation.

Statistically significant differences were found between GC and GQ in the total API scores of the subscales of substance use characteristics, dependence diagnoses, effects of substance use on the user, and cravings. These values were higher in GC than GQ (Table 3).

In addition, the MAAS score was statistically higher in GQ in comparison with GC $(\mathrm{p}<0.001)$ (Table 3$)$.

There was a negative relationship between the total API and MAAS scores for the whole sample. As the API score increased, the MAAS score decreased $(\mathrm{p}<0.001)$ (Table 4$)$.

The patients were divided into three groups based on their API scores of dependence severity: low, moderate or high. As API scores increased from low to high, the MAAS score demonstrated a corresponding decrease (Table 5). Upon comparing the API groups given their total MAAS scores, significant differences were found between API groups of low and high severity $(\mathrm{p}<0.001)$ and between the groups of moderate and high severity $(\mathrm{p}<0.05)$, although no significant difference was found between the groups of low and moderate severity.
Table 4. API total score and MAAS total score relationship in the whole sample

\begin{tabular}{|l|c|c|}
\hline & $r^{*}$ & $p$ \\
\hline MAAS total & -0.456 & $<0.001$ \\
\hline
\end{tabular}

API: Addiction Profile Index; MAAS: Mindfulness Attention Awareness Scale. $r^{*}$ : pearson correlation coefficient.

Table 5. The Relationship Between API-subgroups and Mindfulness

\begin{tabular}{|l|c|c|c|c|}
\hline & $\begin{array}{c}\text { API low } \\
(\mathrm{n}=17)\end{array}$ & $\begin{array}{c}\text { API moderate } \\
(\mathrm{n}=48)\end{array}$ & $\begin{array}{c}\text { API high } \\
(\mathrm{n}=99)\end{array}$ & $\mathrm{p}^{*}$ \\
\hline $\begin{array}{l}\text { MAAS total } \\
\text { Median [Min-Max] }\end{array}$ & $83[60-90]$ & $81[38-90]$ & $75[36-90]$ & $<0,001$ \\
\hline
\end{tabular}

$\mathrm{p}^{*}$ : $\mathrm{p}$ value obtained by appealing Kruskal Wallis.

MAAS: Mindfulness Attention Awareness Scale; API: Addiction Profile Index.

\section{Discussion}

To our knowledge, this is the first study in literature to evaluate the relationship between the level of trait mindfulness, severity of cannabis dependence and capacity to quit cannabis use. During the follow-up period of our study, we found that the level of trait mindfulness was significantly higher in GQ, or those that quit cannabis use, in comparison with GC, composed of individuals that tested positive for cannabis in at least one drug test. This result is consistent with other research studies that have reported that higher levels of mindfulness are negatively related with substance use frequency ${ }^{43,44}$. All individuals are born with the capacity to exercise mindfulness, although they may possess varying levels of the trait. Trait mindfulness may be an important determining factor of the ability to quit substance use and achieve remission. Furthermore, when we compared the relationship between level of trait mindfulness and history of use of substances other than cannabis across the whole sample, trait mindfulness was significantly lower in the group with history of using substances other than cannabis. Mixed substance abuse can result in serious problems, such as suicide ${ }^{45}$. Mindfulness-based interventions are reported to reduce alcohol and other substance use/abuse cases ${ }^{14}$.

We found a statistically significant relationship between trait mindfulness and dependence severity. In the whole sample, as the mindfulness level lowered, the severity of dependence level increased. Similar with our data, Vidrine et al. ${ }^{46}$ reported higher mindfulness levels in nicotine-dependent individuals with lower dependence severities. Other studies have reported that individuals with high dependence severity have more problems in social, work and family life 47,48 , and more intensive treatment and support are needed in these cases ${ }^{49}$. This evidences that increasing mindfulness may correlate with decreasing dependence severity and other problems caused by substance dependence. In the other hand high dependence severity level is related with severe chronic substance use; the level of mindfulness might have been decreased as substance

Table 3. Comparison of API subscales' values. API total values. MAAS total values between the groups

\begin{tabular}{|c|c|c|c|c|c|}
\hline & \multicolumn{2}{|c|}{ Group Continue $(n=79)$} & \multicolumn{2}{|c|}{ Group Quit ( $n=85)$} & \multirow[t]{2}{*}{$p^{*}$} \\
\hline & Ave $\pm S D$ & Median [Min - Max] & Ave $\pm S D$ & Median [Min - Max] & \\
\hline The characteristic of substance use & $5.4 \pm 0.3$ & $5.4[4.3-6.4]$ & $4.9 \pm 0.7$ & $5.3[2.3-6.9]$ & $<0.001$ \\
\hline Dependency diagnosis & $21.9 \pm 1.8$ & $21.5[18-29]$ & $21.1 \pm 1.4$ & $21[13-23.5]$ & 0.018 \\
\hline The effects of substance use on the user & $26.3 \pm 7.1$ & $24[11-48]$ & $22.1 \pm 4.9$ & $20[15-37]$ & $<0.001$ \\
\hline Cravings & $9.8 \pm 2.9$ & $9[4-19]$ & $7.7 \pm 2.1$ & $8[4-13]$ & $<0.001$ \\
\hline Motivation to quit using substances & $11.6 \pm 2.9$ & $12[5-15]$ & $10.8 \pm 3.6$ & $12[3-16]$ & 0.216 \\
\hline API total & $15.3 \pm 2.0$ & & $13.7 \pm 1.8$ & & $<0.001$ \\
\hline MAAS total & $69.4 \pm 15.3$ & $74[36-90]$ & $78.4 \pm 10.7$ & $80[46-90]$ & $<0.001$ \\
\hline
\end{tabular}

API: Addiction Profile Index; MAAS: Mindfulness Attention Awareness Scale.

*: $p$ value obtained by applying $t$ test.

Ave: average; SD: standard deviation. 


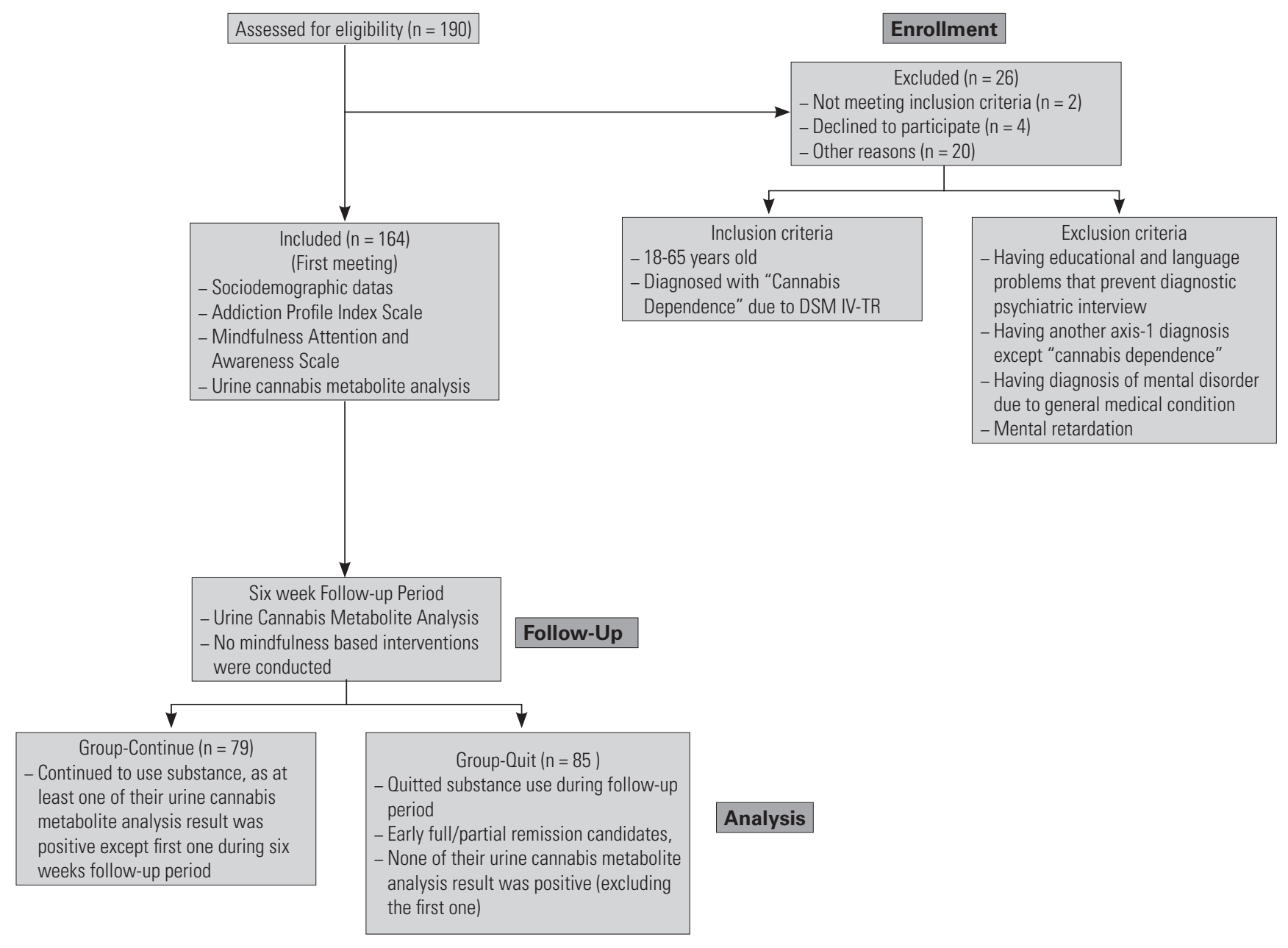

Figure 1. Flow diagram of the study.

use might negatively influence attention and awareness. We divided our sample into three groups according to dependence severity as scored by the API: low, moderate, and high. As API scores increased from low to high, MAAS scores significantly decreased. There were significant differences between API groups of low and high severity $(\mathrm{p}<0.001)$ and between groups of moderate and high severity ( $\mathrm{p}<0.05)$; however, no significant difference was found between groups of low and moderate severity. This may be indicating that individuals with low and moderate dependence could benefit from similar interventions, yet highly dependent individuals may need more intensive interventions. Additional complications and loss of functionality are observed in individuals with high levels of dependence, and treating this group is more difficult. Increasing levels of mindfulness may be an important, effective and new treatment model for individuals with high dependence in order to encourage abstinence and reduce the severity of substance dependence.

We found that the API scores considering substance use characteristics, dependence diagnosis, effects of substance use on the user, and cravings were statistically significantly lower for GQ than GC. Furthermore, the prevalence of substance abuse and associated life problems, history of legal problems, level of substance dependence, and effects of substance use on the user were all lower in GQ in comparison with GC; these results are consistent with the nature of dependence. Cravings is another parameter that results in incompliance with treatment and relapse during treatment of substance dependence ${ }^{50-52}$. In our study, cravings were higher in GC than GQ. These findings were consistent with the studies of Bowen et al. (2009) and Vidrine et al. (2009) that focused on the relationship between different aspects of mindfulness and substance use. The severity of cravings may be decreased by increasing an individual's level of mindfulness. This finding may imply that mindfulness-based treatments could be proposed as new and effective treatment models for cannabis dependence.

It seems to be a paradox that the ratio of individuals that consider cannabis use to be a problem is not statistically significantly different between in GC and GQ, even though the level of mindfulness of GC was significantly lower than GQ. GC also reported a statistically higher history of legal problems, which could be explaining this result.

\section{Limitations}

In the study period, no female individuals with cannabis dependence were involved, so the relationship between gender and level of mindfulness could not be evaluated. The API scale was a selfreported scale, and this may be one limitation of our study. MAAS was the only scale used to measure mindfulness in our study, based on a Turkish validity and reliability search. MAAS measures acting with awareness, only one component of mindfulness, so this may be another limitation. The data in our study were collected crosssectionally, yet whether or not mindfulness-based treatment methods could improve mindfulness levels or provide benefits in cannabisdependent patients is unable to be directly determined. 


\section{Recommendations}

As we determined the negative relation between trait mindfulness level and cannabis use behavior, this may encourage the expansion of mindfulness based interventions in cannabis dependence. Also longterm follow-up studies are needed to evaluate if chronic substance use decrease mindfulness levels of individuals. In addition further cross-sectional and follow up studies are needed in substance use disorders other than cannabis which evaluate the effect of trait mindfulness on treatment results.

\section{References}

1. Breakey WR, Goodell H, Lorenz PC, McHugh PR. Hallucinogenic drugs as precipitants of schizophrenia. Psychol Med. 1974;4(3):255-61.

2. Caspari D. Cannabis and schizophrenia: results of a follow-up study. Eur Arch Psychiatry Clin Neurosci. 1999;249(1):45-9.

3. Halikas JA, Goodwin DW, Guze SB. Marihuana use and psychiatric illness. Arch Gen Psychiatry. 1972;27(2):162-5.

4. Hall W, Solowij N. Adverse effects of cannabis. Lancet. 1998;352(9140):1611-6.

5. Ögel K, Uğuz S, Sir A, Yenilmez Ç, Tamar M, Çorapçioğlu A, et al. Türkiye» De İlköğretim Ve Ortaöğretim Gençliği Arasında Esrar Kullanım Yaygınlığı. J Dependence. 2003;4:15-9.

6. Tennant FS, Groesbeck CJ. Psychiatric effects of hashish. Arch Gen Psychiatry. 1972;27(1):133-6.

7. Budney AJ, Vandrey RG, Stanger C. [Pharmacological and psychosocial interventions for cannabis use disorders]. Rev Bras Psiquiatr. 2010;32 Suppl 1: S46-55.

8. Agosti V, Levin FR. Predictors of treatment contact among individuals with cannabis dependence. Am J Drug Alcohol Abuse. 2004;30(1):121-7.

9. Carroll KM, Easton CJ, Nich C, Hunkele KA, Neavins TM, Sinha R, et al. The use of contingency management and motivational/skills-building therapy to treat young adults with marijuana dependence. J Consult Clin Psychol. 2006;74(5):955-66.

10. Stephens RS, Roffman RA, Simpson EE. Treating adult marijuana dependence: a test of the relapse prevention model. J Consult Clin Psychol. 1994;62(1):92-9.

11. Connors GJ, Maisto SA, Donovan DM. Conceptualizations of relapse: a summary of psychological and psychobiological models. Addiction. 1996;91(12s1):5-14.

12. Dixon L, McNary S, Lehman AF. Remission of substance use disorder among psychiatric inpatients with mental illness. Am J Psychiatry. 1998;155(2):239-43.

13. McLellan AT, Lewis DC, O’Brien CP, Kleber HD. Drug dependence, a chronic medical illness: implications for treatment, insurance, and outcomes evaluation. JAMA. 2000;284(13):1689-95.

14. Chiesa A, Serretti A. Are mindfulness-based interventions effective for substance use disorders? A systematic review of the evidence. Subst Use Misuse. 2014;49(5):492-512.

15. Irvin JE, Bowers CA, Dunn ME, Wang MC. Efficacy of relapse prevention: a meta-analytic review. J Consult Clin Psychol. 1999;67(4):563-70.

16. McHugh RK, Hearon BA, Otto MW. Cognitive behavioral therapy for substance use disorders. Psychiatr Clin North Am. 2010;33(3):511-25.

17. Hayes SC. Acceptance and commitment therapy, relational frame theory, and the third wave of behavioral and cognitive therapies. Behav Ther. 2004;35(4):639-65.

18. Çatak PD, Ögel K. Farkindalik temelli terapiler ve terapötik süreçler. Klinik Psikiyatri. 2010;13:85-91.

19. Baer RA. Measuring mindfulness. Contemporary Buddhism. 2011;12(1):241-61.

20. Kabat-Zinn J. Mindfulness-based interventions in context: past, present, and future. Clin Psychol Sci Pract. 2003;10(2):144-56.

21. Kabat-Zinn J. Wherever you go, there you are: mindfulness meditation in everyday life. Hyperion; 1994. 316 p.

22. Karyadi KA, VanderVeen JD, Cyders MA. A meta-analysis of the relationship between trait mindfulness and substance use behaviors. Drug Alcohol Depend. 2014;143:1-10.

23. Baer RA, Smith GT, Hopkins J, Krietemeyer J, Toney L. Using self-report assessment methods to explore facets of mindfulness. Assessment. 2006;13(1):27-45.
24. Brown KW, Ryan RM. The benefits of being present: mindfulness and its role in psychological well-being. J Pers Soc Psychol. 2003;84(4):822-48.

25. Bowen S, Chawla N, Marlatt GA. Mindfulness-based relapse prevention for the treatment of substance-use disorders: A clinician's guide. New York, NY: Guilford Press; 2010.

26. Marlatt GA, Donovan DM. Relapse prevention: maintenance strategies in the treatment of addictive behaviors.New York: Guilford Press; 1985.

27. Teasdale JD, Moore RG, Hayhurst H, Pope M, Williams S, Segal ZV. Metacognitive awareness and prevention of relapse in depression: empirical evidence. J Consult Clin Psychol. 2002;70(2):275-87.

28. Bowen S, Enkema MC. Relationship between dispositional mindfulness and substance use: findings from a clinical sample. Addict Behav. 2014;39(3):532-7.

29. Tiffany ST. A cognitive model of drug urges and drug-use behavior: role of automatic and nonautomatic processes. Psychol Rev. 1990;97(2):147-68.

30. Baker TB, Morse E, Sherman JE. The motivation to use drugs: a psychobiological analysis of urges. Nebr Symp Motiv. 1986;34:257-323.

31. Khantzian EJ. The self-medication hypothesis of addictive disorders: focus on heroin and cocaine dependence. Am J Psychiatry. 1985;142(11):1259-64.

32. Bowen S, Witkiewitz K, Chawla N, Grow J. Integrating mindfulness meditation and cognitive behavioral traditions for the long-term treatment of addictive behaviors. JCOM. 2011;18(10):473-9.

33. Brewer JA, Sinha R, Chen JA, Michalsen RN, Babuscio TA, Nich C, et al. Mindfulness training and stress reactivity in substance abuse: Results from a randomized, controlled stage I pilot study. Subst Abus. 2009;30(4):306-17

34. Vieten C, Astin JA, Buscemi R, Galloway GP. Development of an acceptance-based coping intervention for alcohol dependence relapse prevention. Subst Abus. 2010;31(2):108-16.

35. Zgierska A, Rabago D, Zuelsdorff M, Coe C, Miller M, Fleming M. Mindfulness meditation for alcohol relapse prevention: a feasibility pilot study. J Addict Med. 2008;2(3):165-73.

36. Baer RA. Mindfulness training as a clinical intervention: A conceptual and empirical review. Clin Psychol Sci Pract. 2003;10(2):125-43.

37. Breslin FC, Zack M, McMain S. An information-processing analysis of mindfulness: Implications for relapse prevention in the treatment of substance abuse. Clin Psychol Sci Pract. 2002;9(3):275-99.

38. Shapiro SL, Carlson LE, Astin JA, Freedman B. Mechanisms of mindfulness. J Clin Psychol. 2006;62(3):373-86.

39. Brewer JA, Bowen S, Smith JT, Marlatt GA, Potenza MN. Mindfulnessbased treatments for co-occurring depression and substance use disorders: what can we learn from the brain? Addiction. 2010;105(10):1698-706.

40. de Dios MA, Herman DS, Britton WB, Hagerty CE, Anderson BJ, Stein MD. Motivational and mindfulness intervention for young adult female marijuana users. J Subst Abuse Treat. 2012;42(1):56-64.

41. Ögel K, Evren C, Karadağ F, Gürol T. Bağimlilik Profil İndeksi'nin (BAPI) Geliştirilmesi, Geçerlik ve Güvenilirliği. Türk Psikiyatri Dergisi. 2012;23(4):264-73.

42. Özyeşil Z, Aslan C, Kesici Ş, ve Deniz ME. Bilinçli farkındalık ölçeği’ni Türkçeye uyarlama çalışması. Eğitim ve Bilim. 2011;36(160):224-35.

43. Black DS, Sussman S, Johnson CA, Milam J. Trait mindfulness helps shield decision-making from translating into health-risk behavior. J Adolesc Health. 2012;51(6):588-92.

44. Bramm SM, Cohn AM, Hagman BT. Can Preoccupation with alcohol override the protective properties of mindful awareness on problematic drinking? Addict Disord Their Treat. 2013;12(1):19-27.

45. Ögel K, Karali A, Tamar D, Çakmak D. Alkol Ve Madde El Kitabi. Bakırköy Ruh ve Sinir Hastalikları Hastanesi; 1998.

46. Vidrine JI, Businelle MS, Cinciripini P, Li Y, Marcus MT, Waters AJ, et al. Associations of mindfulness with nicotine dependence, withdrawal, and agency. Subst Abus. 2009;30(4):318-27.

47. Calsyn DA, Saxon AJ, Bush KR, Howell DN, Baer JS, Sloan KL, et al. The Addiction Severity Index medical and psychiatric composite scores measure similar domains as the SF-36 in substance-dependent veterans: concurrent and discriminant validity. Drug Alcohol Depend. 2004;76(2):165-171.

48. Richter D, Eikelmann B, Berger K. Use of the SF-36 in the evaluation of a drug detoxification program. Qual Life Res. 2004;13(5):907-14.

49. McLellan AT, Woody GE, Metzger D, McKay J, Durell J, Alterman AI, et al. Evaluating the effectiveness of addiction treatments: reasonable expectations, appropriate comparisons. Milbank Q. 1996;74(1):51-85. 
50. Bowen S, Marlatt A. Surfing the urge: brief mindfulness-based intervention for college student smokers. Psychol Addict Behav. 2009;23(4):666-71.

51. Hartz DT, Frederick-Osborne SL, Galloway GP. Craving predicts use during treatment for methamphetamine dependence: a prospective, repeated-measures, within-subject analysis. Drug Alcohol Depend. 2001;63(3):269-76.

52. Shiffman S, Gwaltney CJ, Balabanis MH, Liu KS, Paty JA, Kassel JD, et al. Immediate antecedents of cigarette smoking: an analysis from ecological momentary assessment. J Abnorm Psychol. 2002;111(4):531-45. 